\title{
Possibilities for Optimal Fiscal Policy-Making in the European Union
}

\author{
Marta Postula \\ Ministry of Finance \\ 12 Swietokrzyska St., 00-916 Warsaw, Poland \\ Tel: +48-601-379-653 E-mail: chmsiu1@poczta.onet.pl
}

Received: December 12, 2011

Accepted: January 16, 2012 Published: March 15, 2012

doi:10.5430/rwe.v3n1p20

URL: http://dx.doi.org/10.5430/rwe.v3n1p20

\begin{abstract}
Starting from 2008 worsening crisis events had grave repercussions for the state of public finances in the Euro-zone and the EU. Within a short time, debt to GDP ratios for the sector of government and local institutions rapidly soared across almost all EU member states, therefore shattering modest progress in consolidating public finances achieved in the pre-crisis period. The optimal fiscal policy is expected to stimulate stable and sustainable economic growth in the medium and long term. However, against a backdrop of worsening economic crises in numerous EU member states, it is difficult to talk about maximization of economic effectiveness. In 2011 and 2012 the key issues deal with progress in consolidating public finances through measures on a national level, as well as through early concentration of resources facilitating the growth under flagship initiatives, and through slowing the pace of public debt increase. Restoring budget discipline and macroeconomic sustainability, along with putting in place structural reforms, appears to be a principal issue to "European assessment period" also called "European Semester".
\end{abstract}

Keywords: Public Finance, the Stability and Growth Pact, Fiscal Policy

\section{Introduction}

Identification of the basic criterion for the optimal fiscal policy stands centre to economists explorations. Essentially the researchers and analysts are not focused on the theoretical aspect but on the more practical dimension. Typically analyses examine policy pursued by the parliament and government in a specific country and within a specified time, through the prism of commonly accepted principles that only differentiate in terms of particular conditions by the economic schools of thought. The optimal fiscal policy is expected to stimulate stable and sustainable economic growth in the medium and long term. However, against a backdrop of worsening economic crises in numerous EU member states, it is difficult to talk about maximization of economic effectiveness. The more desirable issues are centred around community oriented and responsible joint decision-making on the future destiny of Community countries, in the name of the accepted political level for economic interventionism.

The hypothesis may be formulated that the possibilities for determining the optimal fiscal policy in the European Union are limited and subject to the political consensus on decisions made. It principally results from previous omissions when some countries overly focused on instruments dealing with deficit and short-term perspective, instead of on the long-term horizon of government operations. It is also necessary to bear in mind the ramifications of the hugely overestimated credit standing of the eurozone members which failed to conduct a stringent fiscal policy, while having a government debt considerably exceeding the threshold of $60 \%$ GDP.

\section{Fiscal Policy in the Theory of Economics and Economic Policy of Countries}

In economics, major differences in approaches held by specific schools pertain to the impact of public spending on the economic growth. According to the theory of the effective demand defined by John Keynes (1883-1946), with incomplete exploitation of factors of production, each autonomous increase in total private investments, budget deficit and export surplus triggers an increase in employment and national income. Increasing public spending has positive effects on growth. In the context of the neoclassical theory, boosting demand does not prompt an increase in income; prices only soar without any impact on the magnitude of output and employment. Rising public expenditures only lead to a squeeze in private spending. This specific process is called the crowding out effect. In the view of neoclassical economists, increasing spending fails to drive economic growth, and the crowding out of private spending by public spending brings downright negative consequences for growth due to their lower effectiveness. A fusion of both theories was carried out in the form of the neoclassical synthesis (Hicks, Hansen, 1949). Central to the theory of growth is the 
concept of so-called non-Keynesian effects of demand modelling policy originated by this doctrine. Permanent reduction of public expenditure lifts the expectations which therefore spur increased private expenditures; compensating the effects of decreasing public spending with extra gains. Reduction in public expenditure entails decline in deficit and debt, as well as a fall in interest rates. As a consequence, this enables increased consumption and investment spending. In compliance with the doctrine of the neoclassical synthesis, for a country with a relatively high deficit and public debt, positive growth effects result from a cutback in public spending.

At the turn of the $80 \mathrm{~s}$ and $90 \mathrm{~s}$ of the $20^{\text {th }}$ century James Williamson (Williamson, 1990) formulated a set of recommendations for economic policy known as the Washington consensus. This set of guidelines was originally developed for implementation in Latin America. Its universal formula encouraged its widespread use in other countries experiencing economic turbulence or undergoing economic transformation. These recommendations were advocated by the International Monetary Fund and World Bank. To a large extent, similar overtones are retained by the European Union documents, such as the Stability and Growth Pact, which setting principles and updated trends for economic policy. With regard to fiscal policy, the Washington consensus encouraged fiscal discipline and redirecting public expenditures towards fields with high economic returns and the potential to improve income distribution. Other recommendations of the consensus included privatization, measures for liberalizing and deregulating markets, lowering interest rates and expanding the tax base. Regardless of the economic school of thought as the analysis basis, one of the essential goals of the rational fiscal policy is to maintain the size of the public debt within rational limits. Yet it should be stressed that, for both theoretical and quite practical reasons, a direct parameter to be subject to ongoing modification and oversight is deficit, not debt. Most deliberations, proposed rules and instruments issued for implementation by fiscal and monetary authorities focus on deficit. Debt is largely a result of shifts in foreign exchange rate and GDP itself. Operations on debt rely on debt securities management. More marginalized issues relate to size of debt outstanding and issuance in each fiscal year, frequently comparable to the size of total annual budget income/expenditures. We dealt with a sort of neglecting the scale of the overall public debt by countries which had long managed their debts efficiently without any obstacles in rolling debt. Systematic, continuous and originally almost inconspicuous loss of confidence by financial markets towards countries with the highest debt to GDP ratio, in a surprisingly unexpected manner (though there was nothing surprising) gave rise to debt crisis. Addressing this problem will require painful reduction of debt (commonly, but not adequately in the case of state units denoted as bankruptcy).

It may be noticed that debt for government and local government institutions sector in the EU states, eurozone (limited to the original group of 12 states) and in Germany, Spain, France, Italy, Poland, Great Britain, the United States, Japan was continually growing within the years 1990, 1995, 2000, 2005, 2010.

\section{$<$ Table 1 about here $>$}

First, reference value of $60 \%$ for debt to GDP ratio (constituting, along with deficit, an element for fiscal criterion) is repeatedly exceeded by an average ratio for the eurozone countries. Moreover, an average ratio for the whole EU is lower within all years specified. The major EU countries: Germany and France reported a similar dynamic for the ratio increase from safe levels in the $90 \mathrm{~s}$ up to over $80 \%$ in 2010 . Italian debt hit a level of $100 \%$ within the period examined, only to reach, except for brief ratio contractions, almost $120 \%$ in 2010 . The situation for Spain was clearly more stable where the ratio exceeded the limit just at the end of the period, attaining $61 \%$. Debt in Great Britain fluctuated around $40 \%$ just to approach $80 \%$ in 2010 due to the considerable costs of propping up the banking sector.

The situation of the countries enjoying the highest reputation among creditors appears interesting. For the USA the debt ratio reached over $95 \%$ whereas for Japan it topped almost $200 \%$. All countries recorded a sharp surge in debt in recent years which was connected with public expenditure for stimulus measures and rescue packages for the crisis-hit banking sector. The annual deficits in relation to GDP tended to exceed $10 \%$ and this trend could not be halted by regulations on excessive deficit.

Essentially, public debt is a result of state's liabilities arising from issuance of securities by the government and local government sectors. Treasury bonds and bills are a specific form of borrowing money, whereas securities confirm the creditor-debtor relationship between public authorities and lenders. Entities in the public finances sector, including the government and local government sector, also contract direct loans and credits. Debt also results from non-payment of liabilities due by units in the public sector.

The key reason underlying public debt is financing the budget deficit projected in the budget act. Financing the budget deficit through incurring public debt automatically generates costs that will be a government expenditure in the future. While adopting the budget providing for deficit, the state authorities bear significant responsibility for its financing, that is finding loan sources, as well as for its repayment together with interest. 
Public debt is a particularly costly way for financing public expenditures. Its peculiarity refers to the necessity of subsequent reimbursement of the debts together with interest. Public debt servicing costs diminish future spending capabilities of the state (including those on significant development goals) and frequently impel to contract further loans. A crucial element for the analysis of the public debt burden is the time factor. The point is that the moment of contracting the loans differs from the moment of repaying the debt. In some cases the difference may even be several years as e.g. debts incurred by governments during a war which financial consequences are suffered by following generations. Thus we now confront the issue of debt burden and inter-generational income redistribution where its extent and effects are easily determined. A remarkably important determinant for this assessment is the goal for which public loans are incurred. In the case of funding economic infrastructure to be built over many years with long construction project timescales and with subsequent exploitation time of several decades, this is generations assuming financial ramifications of public loans servicing who make use of the facilities financed by means of public borrowings. A totally different situation occurs when loans incurred are allocated for financing ongoing expenditures which fail to yield any benefits in the long run at their maturity. Yet other consequences are brought by financing public debt using papers with short maturity which pushes governments to roll over a significant portion of the debt. Swings in sentiment on financial markets have a great influence on capabilities to finance debt.

Numerous states individually adopt statutory measures imposing rational fiscal policy. I would like to explore three examples of solutions implemented in Poland, Switzerland and Brazil, with regard to the outlined issue of constraining excessive debt. Then the Community rules for shaping fiscal policy in the EU states will be discussed, with a special focus on preventing excessive indebtedness.

\section{Case Studies of Rational Fiscal Economy: Poland - Switzerland - Brazil}

It is of paramount significance to analyze and confront selected tools applied in the fiscal policy in three selected states belonging to various transnational organizations, i.e. the European Union (Poland), European Free Trade Association (Switzerland) and Common Southern Market (Brazil).

In the case of Poland, as well as other states which underwent regime transformation in recent decades, specific drivers stem from the aftermath of long-standing problems in grappling with deficit. The necessity to oversee deficit and debt of the public sector brings substantial pressure to decrease public expenditure. In Poland a major fiscal rule is so-called debt, laid out in two legal acts - The Constitution of the Republic of Poland and the Act on Public Finances of 27 August 2009 (first passed in the Act on Public Finances of 26 November 1998). The constitutional rule determining a limit for public debt inhibits contracting loans or providing guarantees and financial sureties which would cause state public debt to exceed three-fifths of the value of the annual GDP, consistent with Article 104 (104c) of the Treaty establishing the European Community (the Maastricht Treaty of 7 February 1992), notably with Article 1 of the Protocol on he excessive deficit procedure (annexed to the Maastricht Treaty). This rule is complemented by the statutory rule setting prudent thresholds with regard to government deficit, through putting in place thresholds for government debt to GDP ratio at $50 \%, 55 \%$ and $60 \%$. Exceeding these limits results in the introduction of prudential and remedial procedures.

In the case when the debt to GDP ratio is greater than $50 \%$ but not more than $55 \%$, the squeeze on government budget deficit is put in place for a consecutive fiscal year up to the ratio resulted from the budget act on the current fiscal year. In the case of another prudent threshold ranging from $55 \%$ up to $60 \%$, the limit imposed involves freezing remuneration in the public sector, suspending expenditures on new investments and restricting indexation of retirements and other pensions. Accordingly, the Council of Ministers is obliged to review budget expenditures being financed by funds coming from foreign loans, as well as to inspect long-term investments. The Council of Ministers submits the Sejm (lower chamber of Parliament) with a recovery programme intended to decrease this ratio. Additionally, in the fiscal year following the year when immature liabilities from sureties and guarantees provided by the State Treasury to GDP ratio was announced, a ban on exceeding the ratio announced comes info force. The Minister of Finance, in the manner of the official announcement, notifies about the ban period for exceeding the ratio within the fiscal year following after the year when the ratio was announced. The ban period may be shorter than the actual fiscal year. Furthermore, expenditures by local government units may be higher than revenues from the budget increased by budget surplus from preceding years and available funds, solely by an amount related to accomplishing tasks utilising the European Union funds and other assistance funds not subject to reimbursement.

In the event that the ratio exceeds $60 \%$ the Council of Ministers, despite previous restrictions, is obliged to submit a recovery programme to the Sejm in order to shrink the ratio to the lowest level. Alongside, there are launched limits on budget expenditures by local government units which cannot be higher than revenues of the budget, as well as a prohibition on granting new sureties and guarantees by the units of the public finances sector. To reduce the increase in government debt it is necessary to take direct austerity measures on expenditures, measures which should be boosted by 
relevant institutional frameworks.

The structural foundation for fiscal imbalance, coupled with the effects of the world crisis contributed to a rapid rise in public debt in Poland. In 2010 public debt to GDP ratio exceeded the first statutory prudent threshold (50\%) running the risk of exceeding the successive threshold of $55 \%$ in the following year. Activities geared to cure public finances mitigated the threat of materializing this risk. In view of excessive deficit there is still a necessity to tighten a fiscal policy. Above all, restraining an increase in public debt requires reduction of public expenditure, since tax rises would jeopardize any acceleration of economic growth in following years.

Regardless of other reasons, relatively slighter shifts in debt to GDP ratio in Poland (contrary to other European states) should be assigned to consequences of the constitutional debt limit having been applicable for 14 years. It constitutes, together with lower prudent thresholds, a clear boundary for projecting and then realizing public expenditures.

In the country, regarded as the most stable and one of the wealthiest, that is Switzerland, there are two fiscal rules applicable: expenditure, that is expenditure restraint, as well as debt one that is debt restraint which are reflected in relevant legal regulations (BV, FHG, 2010). The Constitution of Switzerland contains an overall requirement for balancing public revenues and expenditures in a specified period. Over time, however, it proved necessary to insert detailed regulations addressing so called debt restraint, specifying a method for balancing public revenues and expenditures in a given period, into this act. In 2000 relevant amendments (to Article 126) were formulated in the Constitution which in 2001 were adopted through a referendum. In accordance with these regulations the referred rule begin to be effective following a two-year transitional period, that is from 2003.

In Brazil two types of rule are in use: expenditure and debt. A mechanism behind the expenditure rule involves few legal regulations. The constitution sets up a budget directives tool adopted in the form of an act which defines targets and priorities for the federal government, including capital expenditures for the consecutive fiscal year, guidelines for formulating an annual budget act, amendments in tax legal provisions and investment policy. In accordance with regulations, the act on budget directives is intended to safeguard a balance between revenues and expenditures, as well as to include an annex setting fiscal objectives (annual goals, in constant and present values, for revenues and expenditures, government debt for a current year and two consecutive fiscal years). Draft budget laws need to be drawn up in accordance with guidelines included in the act on budget directives. Brazilian legislation also sets out correction mechanisms - when a decline in revenues is recorded which therefore put at risk delivering the goals specified in the annex defining fiscal objectives, actions are undertaken to curtail incurring liabilities and conducting financial transactions (pursuant to criteria laid out in the act on budget directives) (Postula, 2011).

With regard to the Constitution, the mechanism behind the rule asserts that the right to setting binding and legal limits on government debt is vested into the Senate of Brazil. The Senate determines, based on the Presidents motion, limits on consolidated government debt divided between specific federal regional and local authorities. Whereas the Congress adopts the act imposing the limits on federal debt from issuance of Treasury securities. Obviously in this case, as in the previous one, correction mechanisms were projected - compliance with the limit is monitored in 4-moths periods. Exceeding the debt limit by a specific administrative unit of the Federation implies an obligation to cut back on the limit in the subsequent period by at least $25 \%$. Also, it results in restriction on incurring new liabilities (except for refinancing the debt) and constraints on transfers from the budgets: both federal and state. There is also a provision in state and local legislation to determine debt limits at the level lower than those applicable in the national law.

Given the solutions illustrated with respect to applicable fiscal rules in three states being at various levels of social and economic advancement, it underlines an unequivocal statement that it is a common tool for effective fiscal policy with regard to modelling a level of public expenditures and debt. Obviously accurate solutions in this regard pertain to the specifics of a certain country which makes any comparison difficult.

\section{State of Public Finances in the Euro-zone and the EU}

Starting from 2008 worsening crisis events had grave repercussions for the state of public finances in the Euro-zone and the EU. Within a short time, debt to GDP ratios for the sector of government and local institutions rapidly soared across almost all EU member states, therefore shattering modest progress in consolidating public finances achieved in the pre-crisis period. At the end of 2010 debt to GDP in the sector of government and local government institutions hit almost $85.6 \%$ in the Euro-zone and around $80.3 \%$ in the entire EU, that is about 18 and 15 percentage points above the level from 2005 respectively. The current size of deficit and debt results from a fall in public revenues and enhanced pressure on public expenditures, as well as stimulus packages adopted by individual countries. Finances of public units in some EU member states became contingent on, to a large extent, the business cycle or by interim revenue sources. Furthermore, revenue structure contributed to collapse of revenues in units of the public finances sector due to sudden 
contraction of economic operations, whereas their expenditures, in large measure, remained at the level previously projected. In a sense economic policies in the EU member states exploited automatic stabilizers which alleviated the impact of the world crisis on real economies. Yet, it was insufficient to hamper the plunge in demand and prevent risk of crumbling financial systems. Therefore, governments in most EU states also implemented individual stimulus packages under common conditions set out in the European Economic Recovery Plan, launched by the Commission in December 2008 (www.mg.gov.pl). Implemented stimulus packages, based on public expenditures, escalated ongoing difficulties in public finances that were triggered by adverse developments related to population ageing, which in turn translated into the state of public finances. Faced with absence of changes over a long time there emerges a phenomenon of aging which will bring an inevitable significant burden for budgets in individual countries (with implications in the long term). Additionally it will impede recovery in public sector finances which even today remain in a tight corner. Without putting in place profound reforms, public expenditures allocated for pension payments and other related benefits are likely to soar within the coming 50 years by around 4 percentage points of EU GDP (Annual Growth Survey, 2011). In roughly one third EU member states an increase in public spending connected with population aging is likely to hit 7 percentage points of GDP.

Membership of individual countries in political formations has implications for legislative rules of fiscal policy. Requirements for fiscal policy with regard to the EU states were specified in the Treaty on the functioning of the EU, as well as in rules included in the Stability and Growth Pact. Therefore it is widely acknowledged that basic fiscal rules are transnational. These, above all, involve: the necessity to maintain deficit in the sector of government and local government institutions at the level not exceeding 3\% of GDP and obligation to maintain public debt at the level not breaching $60 \%$ of GDP. Striving to achieve medium-term budget target, differentiated for specific EU countries, serves as security against risk of breaching these rules. In the case of Poland, especially close to the author, it corresponds to a structural deficit at $1 \%$ of GDP.

In connection with a clear discrepancy between goals declared in the Stability and Growth Pact and the fiscal situation in the EU states before 2011, the decision was made to make relevant amendments in the Stability and Growth Pact. A starting point for these amendments is Article 104 (3-14) in the Treaty establishing the European Community (TEC) which regulated the conduct procedure by the European Commission and the Council of the European Union in the case of excessive deficit emerging in a specific country. This procedure was specified in the Stability and Growth Pact which stipulates possible sanctions imposed on the country not adjusting its excessive deficit. Such provisions in the Stability and Growth Pact are designed to ensure that fiscal policy pursued by individual member states does not stoke tensions among countries involved in the Economic and Monetary Union.

The Pact comprises of preventive, as well as dissuasive (excessive deficit procedures) elements. Based on the provisions of the preventive arm, member states are obliged to submit annual stability (convergence) programmes, disclosing the manner by which they intend to safeguard sound fiscal positions in the medium term, taking into account the impeding impact of population aging. The Commission assesses these programmes and the Council gives its opinion on them. The preventive arm is carried out though two policy instruments which may be applied to impede "excessive" deficit. The Council, on the grounds of a proposal by the Commission, may address an early warning to prevent the occurrence of an excessive deficit. Using the policy advice, the Commission may recommend a member state to comply with obligations arising from the Stability and Growth Pact. The dissuasive part of the Pact governs the excessive deficit procedure (EDP). The EDP is triggered by the deficit exceeding the 3\% of GDP threshold defined in the Treaty. If it is decided that the deficit is excessive in the meaning of the Treaty, the Council issues recommendations to the member states concerned to correct the excessive deficit and sets a timeframe for accomplishing this target. Failure to comply with the recommendations prompts further steps in the procedures, including the possibility of sanctions for euro area member states. Such legislation was applicable over the recent decade, with certain corrections endorsed in 2005. However, the efficacy of this legislation proved insufficient as confirmed by the outlined data clearly indicating the emergence of the debt crisis at the turn of 2010 and 2011.

In March 2010 the European Council adopted the Europe 2020 strategy setting ambitious targets to foster a new growth path for the EU member states (Communication COM (2010), 2010). Initial declarations made by the member states as to their national goals within five areas agreed on under the Europe 2020 strategy indicate which route the EU has to take to deliver on its ambitions. After all, the strategy launched is not sufficient a measure taken by the EU as the financial crisis also exposed vulnerabilities of the economic management system in the European Union. In 2011 it appeared necessary to undertake further actions to address identified systemic vulnerabilities in consolidation of public finances.

\section{Challenges Faced By the European Union as Regard Budget Policy}


In 2011 and 2012 the key issues deal with progress in consolidating public finances through measures on a national level, as well as through early concentration of resources facilitating the growth under flagship initiatives, and through slowing the pace of public debt increase. Restoring budget discipline and macroeconomic sustainability, along with putting in place structural reforms, appears to be a principal issue to "European assessment period" also called "European Semester". In the light of conclusions drawn at the meeting of the European Council in March till June 2011 the Commission assessed national reform programmes, as well as stability or convergence programmes, and, based on the integrated guidelines related to the Europe 2020 strategy, presented the member states with common recommendations for specific countries, thus providing advice for budget policy under the Stability and Growth Pact. In July 2011 the Council adopted recommendations and opinions with respect to stability and convergence programmes, undertaking additional actions. The 4 members states, working on their budgets for 2012 in the $2^{\text {nd }}$ half of the year, should convert referred recommendations and opinions into definite decisions. In November 2012 a package of six legal acts (so called "Six Pack") intended to enhance surveillance of the budget and public deficit was adopted.

A new set of budget rules in the form of comprehensive recommendations with regard to budgetary frameworks in the EU states was launched by means of the non-statutory document, namely the Council Directive 7. In the directive "budgetary frameworks" means a set of arrangements, procedures, rules and institutions that form a foundation for budgetary policy in the sector of government and local government institutions. The extent of these frameworks was described in great detail. They should embrace systems of budgetary accounting and statistical reporting. It is also advisable to formulate numerical fiscal rules, customized to the specifics of individual states. Fiscal rules are expected to make budgetary policy of the member state comply with obligations stemming from the TEC. Rules should be denominated in a collective rate for budgetary results, e.g. budget deficit for the sector of government and local government institutions, loan needs, debt or their major components. Another element covered in the frameworks are budgetary procedures comprising procedural rules that regulate the budget process at all stages. A new quality should be provided by the medium-term budgetary frameworks that extend the horizon for shaping fiscal policy beyond the annual budgetary calendar and enable to responsibly set policy priorities and medium-term budgetary objectives. In addition, budgetary frameworks are to incorporate arrangements for monitoring and independent analysis to enhance the transparency of elements of the budget process. The last element involves mechanisms and rules that regulate fiscal relationships between public authorities across sub-sectors of general government. The Directive evidently underlines remarkable responsibility of fiscal authorities for turning realistic macroeconomic and budget forecasts into a basis for projections adopted within medium-term budgetary frameworks.

A significant boost to the Stability and Growth Pact was given on 16 November 2011 though adopting four common regulations and one Council regulation by the European Parliament and Council of the European Union. Two of them targeted to the euro area countries deal with the effective enforcement of budgetary surveillance and enforcement measures correct excessive macroeconomic imbalances. The remaining two applicable to the whole EU are devoted to enhancement of the surveillance of budgetary positions, as well as surveillance and coordination of economic policies, and prevention and correction of macroeconomic imbalances. The last resolution aims at speeding up and clarifying the implementation of the excessive deficit procedure and it amends the relevant resolution of 1997 (already previously amended in 2005).

In the case of the euro area countries, sanctions may be imposed for lack of recommended corrective actions. In the preventive part, these sanctions consist in opening interest-bearing deposits of $0.2 \%$ of GDP in a given member state in the previous year. Analogical sanctions in the corrective part of the Stability and Growth Pact, thus in the case of emergence of the excessive deficit, only differ in not having interest. When the reasons for imposition cease to exist they are returned. Further failure to take actions to effectively squeeze the excessive deficit may imply imposing a fine by the Council of at the maximum value calculated in a manner similar to deposits. Also, equally severe money sanctions are imposed for manipulating statistical data by the member states (Regulation L 306/1, 2011).

A new area subject to oversight is a state of macroeconomic balance for member states. The related regulation contains detailed provisions for identifying macroeconomic imbalances in the Union, as well as for preventing excessive macroeconomic imbalances and for correcting these imbalances. The resolution introduces an adequate mechanism for identifying imbalances and procedure with respect to excessive imbalance. The euro area states which fail to comply with approved principles are under threat of sanctions to the amount of $0.1 \%$ of their GDP from the previous year (Regulation L 306/8, 2011).

The processes of economic dialogue were specified, intended to bolster the dialogue among the EU institutions, especially the European Parliament, Council and Commission and to enhance transparency of decisions taken and accountability for their taking. Provisions connected with fiscal targets were expanded. 
Achieving the medium-term objective for budgetary positions should ensure the member states have a safety margin with regard to the $3 \%$ of GDP reference value in order to provide sustainable public finances or rapid progress in its attaining. Regulations should give room for running budgetary policy, with a particular focus on need for public investments. The medium-term budgetary goal needs to be updated regularly on the basis of a jointly agreed method, adequately reflecting the risks of implicit and explicit liabilities for public finances, as embodied in the aims of the Stability and Growth Pact (Regulation L 306/12, 2011).

A special emphasis should be placed on a quick adjustment path towards the medium-term objective for member states where the debt level exceeds $60 \%$ of GDP or with risks for the long-term capacity of debt service.

On assessing the adjustment path towards the medium-term budgetary objective, the Council together with the Commission examine whether the member state pursues an appropriate annual improvement of its cyclically-adjusted budget balance, net of one-off and other temporary measures, required to meet its medium-term budgetary objective, with $0.5 \%$ of GDP as a benchmark. With regard to member states where the debt level exceeds $60 \%$ of GDP or with risks for the long-term capacity of debt service, the Council and the Commission examine whether an annual improvement of its cyclically-adjusted budget balance, net of one-off and other temporary measurers goes beyond $0.5 \%$ of GDP. The Council and the Commission take into account whether a higher adjustment effort is made during boom cycle, whereas the effort might be more restrained in bust cycle.

\section{Conclusions}

A review of changes in public finances implemented by individual countries clearly demonstrates that there is an overall awareness of the necessity for budget consolidation and the need to restore stability in the financial and banking sectors. However, far less attention is devoted to formulating the reforms key to restoring the balance, fostering growth and creating new jobs. Analogous conclusions occur with respect to interim national objectives which clearly imply serious challenges in meeting overriding targets agreed on the EU level. Nevertheless initial data show that differences in goals at the national level and across the EU as a whole are not so immense as to be insurmountable with determined steps in the years ahead. More important is to create a favourable climate right at the beginning to facilitate achieving goals to which all member states are committed, irrespective of their starting point.

In the amended regulation regulating the excessive deficit procedure, it was evidently stated that the rules regarding the budget discipline should be tightened, especially through putting more emphasis on the debt level and its changes, as well as on the overall financial sustainability. It was also underlined that mechanisms governing compliance with these rules and their enforcement need to be augmented. The numerical formula for decreasing debt for countries breaching the $60 \%$ level of GDP was established. In this case it is widely held that public debt to GDP ratio falls sufficiently and then approaches the reference value satisfactorily if over recent three years its gap in relation to the reference value was declining at the average rate of one twentieth per annum, based on the changes over the recent three years disclosed in available data. Otherwise, the excessive deficit procedure is triggered in the state, regardless of the size of the deficit itself (Regulation L 306/33, 2011).

Adopted legislative amendments are immense in scope and scale. Though the foremost among them are enhanced arrangements as to the size of public debt; which suggests that the previous focus on the deficit while neglecting the debt issues has been regarded as a grave mistake.

\section{References}

Annual Growth Survey. (2011). Annex 2 macroeconomic survey, Council of the European Union, Brussels.

Brancaccio, E. \& Fontana, G. (2011). The global economic crisis: new perspectives on the critique of economic theory and policy, Oxon ; New York,110-115.

Bundesgesetz über den eidgenössischen Finanzhaushalt (FHG) - as at 1 January 2010.

Bundesverfassung der Schweizerischen Eidgenossenschaft (BV) - as at 7 March 2010.

Communication from the Commission Europe (2010). 2020 A strategy for smart, sustainable and inclusive growth COM 2020 final version, Brussels.

Council Directive. (2011).2011/85/EU of 8 November 2011 on requirements for budgetary frameworks of the Member States, Official Journal of the European Union L 306/41 of 23 November 2011.

Council Regulation (EU) No 1177/2011 of 8 November 2011 amending Regulation (EC) No 1467/97 on speeding up and clarifying the implementation of the excessive deficit procedure, Official Journal of the European Union L $306 / 33$ of 23 November 2011. 
Kjaer, P. F., Teubner, G. \& Febbrajo, A. (2011), The financial crisis in constitutional perspective : the dark side of functional differentiation, Oxford, Portland, 64-66.

Kolodko, G. (2011). Truth Errors and Lies, Columbia University Press.

Postula, M. (2010). Amelioration et developpement du budget par objectifs en Pologne; Revue Francaise de Finance publiques N 114-Avril 2011, France, 21-22

Postula, M. (2011). Fiscal rules in the world and in Poland, MBA, 34.

Regulation (EU) No 1173/2011 of the European Parliament and of the Council of 16 November 2011 on the effective enforcement of budgetary surveillance in the euro area, Official Journal of the European Union L 306/1 of 23 November 2011.

Regulation (EU) No 1174/2011 of the European Parliament and of the Council of 16 November 2011 on enforcement measures to correct excessive macroeconomic imbalances in the euro area, Official Journal of the European Union L 306/8 of 23 November 2011.

Regulation (EU) No 1175/2011 of the European Parliament and of the Council of 16 November 2011 amending Council Regulation (EC) No 1466/97 on the strengthening of the surveillance of budgetary positions and the surveillance and coordination of economic policies, Official Journal of the European Union L 306/12 of 23 November 2011.

Tanzi, V. (2011). Government versus Markets. The Changing Economic Role of the State,Hardback, New York. http://dx.doi.org/10.1017/CBO9780511973154

Williamson, J. (1990), What Washington Means by Policy Reform, w: Latin American Adjustment: How Much Has Happened? (edited by) J. Williamson, Institute for International Economics, Washington, 12.

http://www.mg.gov.pl/NR/rdonlyres/Europejskiplannaprawygospodarczej.pdf.

Table 1. Public debt in selected countries

\begin{tabular}{|c|c|c|c|c|c|}
\hline Country & 1990 & 1995 & 2000 & 2005 & 2010 \\
\hline \hline EU & $52.7 *$ & $69.7 *$ & 61.9 & 62.8 & 80.3 \\
\hline EA-12 (euro area) & $56.5^{*}$ & 72.4 & 69.5 & 70.6 & 86.3 \\
\hline Germany & $41.3 *$ & 55.6 & 60.2 & 68.5 & 83.2 \\
\hline Spain & 42.7 & 63.3 & 59.3 & 43.0 & 61.0 \\
\hline France & 35.2 & 55.4 & 57.4 & 66.7 & 82.3 \\
\hline Italy & 94.7 & 121.5 & 108.5 & 105.4 & 118.4 \\
\hline Poland &. & 49.0 & 36.8 & 47.1 & 54.9 \\
\hline Great Britain & 33.3 & 51.2 & 41.0 & 42.5 & 79.9 \\
\hline United States of America & 63.6 & 71.2 & 54.8 & 61.8 & 95.2 \\
\hline Japan & 63.9 & 86.2 & 135.4 & 175.3 & 197.6 \\
\hline
\end{tabular}

* in 1990 and 1995 EU-15, later EU-27; in 1990 data related to FRD

Source: author's study on the basis of the data from the European Commission 